\title{
Apartment quality during warranty period of building
}

\author{
Eliza Gumerova ${ }^{1, *}$, Marina Petrochenko ${ }^{1}$, and Vadim Kankhva ${ }^{2}$ \\ ${ }^{1}$ Peter the Great St. Petersburg Polytechnic University, 29, Politechnicheskaya St., St. Petersburg, \\ 195251, Russia \\ ${ }^{2}$ Moscow State University of Civil Engineering, 26, Yaroslavskoye shosse, Moscow, 129337, Russia
}

\begin{abstract}
The article studies process of optimization of cost management structure for improving quality of constructional works in apartment. Property owner has the right to demand the apartment quality during the warranty period. Article 756 of the Civil code of the Russian Federation indicates the limit warranty period as 5 years. Constructional defects can be divided into two categories: general construction and engineering system defects. There are 3 methods, which are applicable to the assessment of apartment quality: $\mathrm{ABC}$, target-costing and life-cycle cost analysis. It is essential to identify the parameters, which can decrease service costs and quantity of defects. Three models of apartment with different conditions are compared. Considering such parameters as the number of defects, the presence of delay in the execution of application, financial loss, presence of repeated complaint from owner, the formula of quality assessment is proposed. New equation allows assessing the quality of the apartment and defining variables, which can influence on it.
\end{abstract}

\section{Introduction}

Limitative warranty period of new building is equal to 5 years according to Civil Code of the Russian Federation. During this period owners have the right to raise demands to property developer. Property management company receives 339 complains from block of 225 flats annually [1]. Thus, average quantity of statements is higher than quantity of owners.

Constructional defects can be divided into two categories: general construction and engineering system defects, depending on work item. $82 \%$ from total quantity of defects are referred to general construction [2,3]. There are defects in finishing works, defects of windows and balcony doors, defects of interpanel joints, defects of roof, defects of leaks in basements and parking areas, the defects of facade and landscaped space. Costs for warranty service amount about 608600 USD per year [4].

The purpose of this article is to develop a model and specify the parameters for assessing the quality of construction work in the apartment. To achieve this goal, the following tasks were set:

1. To consider possible construction defects;

\footnotetext{
*Corresponding author: eliza_gumerova@mail.ru
} 
2. To study the algorithm of elimination of construction defects;

3. Identify the main methods of cost management, which are applicable to assessment of apartment quality;

4. Create a mathematical model to assess the quality of construction works in apartment.

\section{Materials and Methods}

\subsection{Possible constructional defects}

A.V. Belov identifies the method of analyzing the types and consequences of defects as an effective tool for improving quality of construction projects [5].

Constructional defects are detected during the warranty period and are divided into two main groups: general construction and engineering system defects.

Defects of finishing works include defects associated with low quality of finishing works. These include cracks in gypsum board partition, delamination of coating, defects in interior doors and floors $[6,9]$.

Defects of windows and balcony doors include air blow, leakage, window and balcony doors adjustment, defects of fresh air valves. Also the low-quality installation of windows, defects of glass and double-glazed windows.

Balcony defects constitute the biggest part of constructional defects during the warranty period. They include balcony leakages through joints to the facade and balcony slabs, leakages through glazing and canopies, defects in glazing structures and its installation, fittings [7].

Furthermore, property management company received applications about leakages and air blowing through the panels and expansion joints, delamination of the sealant.

Roof defects include leaks and defects of parapet, gutter funnels and storm drains.

Leakages in basements and parking lots at the joints of reinforced concrete structures and in utility lines often appear.

The defects of landscaping include the destruction of coatings of asphalt and paving slabs, failures of coatings, defects of fences and lawns.

Defects of facade are divided into defects of facade finishing (brickwork and wall panels), defects of freezing, defects of window tides.

Defects of engineering systems [8]:

- Electrical;

- Defects in sewer;

- Defects of hot and cold water supplies;

- Defects in heating;

- Ventilation defects;

- Elevator defects;

- Defects in low-current devices.

Electrical defects include defects in electrical wires and equipment, electric accessories, defects in residual current devices and machines, replacement of electric motors [10].

Defects of installation of sewer pipelines, sanitary equipment (toilets, sinks, baths) can occur.

Leakages of pipelines, cold and hot water supplies, defects of shutoff valves, fittings, metering devices, mixing valve, defects of equipment of water metering units and individual heating units.

Heating defects are divided into defects of pipelines, heating system, valves, fittings, compensators, metering devices, radiators, thermostats and equipment of individual heating units. 
Defects of low-current devices include defects of interphone system, TV, radio, Internet. The main defect of such devices is the obstruction of channels.

I. R. Salagor considers, that defects arise due to improper operation, insufficient control of technical condition, lack of design documentation and violations of requirements of regulatory documentation at the stage of operation [11]. It should be noted that the first and last reasons are not warranty cases, because the defects occurred due to the fault of the owner.

\subsection{Elimination of constructional defects}

According to article 724 of the Civil code of the Russian Federation, the customer has the right to submit quality requirements only during the warranty period. Proof of the fact, that defects arose during construction, is one of aspects to eliminate defects with property developer help. Article 756 of the Civil code indicates the terms of detection of improper quality of construction works, the limit warranty period is 5 years. Possible options for eliminating defects during the warranty period (article 723 of the Civil code):

1. Gratuitous elimination of defects within a reasonable time;

2.Proportionate reduction of the price for the work;

3. Reimbursement of expenses for elimination of defects.

Property management company (developer) goes for inspection after getting application for the elimination of defects from the owner of the apartment. Fault detection report is drawn up. Currently, there is no sample of act, but it is necessary to specify the following: the name of the document; a detailed description of subject [12].

Full list of persons, who enter the Commission according to the internal order, is reported. In addition to this, the signatures of each person, participating in the inspection, are affixed at the end to approve the document after its preparation. The decision of Commission is the definition of request type: warranty, operational or commercial. In case of warranty application it is necessary to involve the builder, who performed the work, to eliminate constructional defects.

To oblige the builder to eliminate defects in the works, performed by him, the contract provides for warranty withholding.

The guarantee withholding provides for partial payment upon working completion and signing of the acceptance report to cover possible costs due to improper performance of construction works.

The remaining amount is paid to the contractor within the time after the expiration of the warranty period.

\subsection{Methods of cost management to assess apartment quality}

The choice of cost management method depends on the management objectives and the conditions for its use.

The cost management techniques that apply to assessing the quality of apartment are:

1. ABC method is that the activity is divided into workflows. The cost of product is defined as the sum of the costs incurred to complete processes in the production of the product.

Advantages:

- Reasonable division of overhead factory costs into the costs of types of products;

- Cost formation ranges with the cost of working processes.

Disadvantages:

- Increase in management costs due to changes in the accounting system. 
2. Target-costing. Disposal price and desired profit are set, which determine cost value. This method is possible only with constant interaction between the departments and used to improve the reliability of marketing forecasts.

Advantages:

- Focus on marketing;

- Identify and cost control before product development.

Disadvantages:

- Manufacturing division may not always be able to reduce costs to calculated level.

It is essential to choose right method while modernizing cost management. A. K. Isaev and U. M. Abdyldaev write, that target-costing and kaizen-costing as innovative approaches to cost management in building companies help to reduce costs, stimulate infusion of new technologies, include the cost analysis at all stages of the production process, to achieve the desired profit and require interaction between all departments of organizations. It follows that the target costing and kaizen-costing allow to control constructional costs and are the ways of modernization of cost management system [13].

Dyakov O. V. and Y. V. Abdulaeva wrote about technical difficulties and financial costs of using the models of cost management, their implementation in working system of manufacturing division [14].

3. Life-cycle cost analysis is used in strategic cost management and determines costs throughout the product life cycle.

Benefits:

- Cost estimation and its defrayal throughout the product life cycle;

- Planning of expenses and profits [15].

Drawbacks:

- Overhead costs accounting involves the probabilistic nature of costs.

\section{Results}

Let us consider three models of apartments during warranty period.

Model "A" is characterized by the presence of two or more constructional defects, the absence of builder to eliminate them, the repeated complaint of owner because of delay in execution of the warranty application by developer and statement about indemnification. (Guarantee withholding from builder may offset the refund to the applicant.)

Model "B" - warranty request about one defect, which was executed on time by builder.

Model "C" - "ideal", developer did not receive any application during the warranty period of the object.

Table 1. Parameters of A, B, C models.

\begin{tabular}{|l|l|l|l|}
\hline Model & A & B & C \\
\hline Quantity of defects & 2 and more & 1 & 0 \\
\hline $\begin{array}{l}\text { Application was } \\
\text { executed by }\end{array}$ & $\begin{array}{l}\text { Property } \\
\text { management } \\
\text { company } \\
\text { (Developer) }\end{array}$ & Builder & - \\
\hline Financial loss & $\begin{array}{l}\text { Difference between } \\
\text { indemnification and } \\
\text { guarantee } \\
\text { withholding }\end{array}$ & - & - \\
\hline Consequences & $\begin{array}{l}\text { Increase of warranty } \\
\text { works budget }\end{array}$ & - & - \\
\hline
\end{tabular}




\section{Discussion}

We assume that $\lambda$ is an estimate of apartment quality. $\lambda$ depends on the parameters $a, b, c, d$; where $a$ is the parameter, which characterizes the number of defects, $b$ is the presence of delay in the execution of application, $c$ is financial loss, $d$ is the presence of repeated complaint from owner. Displayed equations are centered and set on a separate line.

Variable $a=(0,1], a \in R . a=1 / m, m$ - number of defects.

If $m=0, a=1 . b, c, d \in Z, 0 \leq b, c, d \leq 1$

In case of execution delay, financial loss and repeated complaint $b=0, c=0, d=0$.

$$
\lambda=\frac{a+b+c+d}{n}=\frac{\sum_{n=1}^{k} x}{k}
$$

where $k$ is the number of factors, which estimate the apartment quality. In this case, $k=4$. Supposition: zero value of one of the parameters, while other parameters are equal to 1 , does not decrease the apartment quality.

Model A:

$$
\lambda=\frac{1 / 2+0+0+0}{4}=\frac{1}{8}=0.125
$$

Model B:

$$
\lambda=\frac{1 / 1+1+1+1}{4}=\frac{4}{4}=1
$$

Model C:

$$
\lambda=\frac{1+1+1+1}{4}=\frac{4}{4}=1
$$

\section{Conclusion}

Property owner has the right to demand the quality of constructional works in the apartment during the warranty period. To reduce the costs of eliminating of constructional defects, it is necessary to develop a structure for optimizing these costs.

The proposed formula of quality assessment considers the parameters, which characterize the number of defects, time and cost parameters. It should be noted that the presence of one application, filed by owner during the warranty period and timely executed by builder, does not reduce the apartment quality.

\section{References}

1. W. Lu, B. Chi, Z. Bao, A. Zetkulic, Building and Environment 155, 247-256 (2019) doi.org/10.1016/j.buildenv.2019.03.050

2. D. Salem, A. Bakr, Z. E. Sayad, Alexandria Engineering Journal 57-4, 3429-3435 (2018) doi.org/10.1016/j.aej.2018.07.014

3. N. Podolyakina, Procedia Engineering 178, 558-568 doi.org/10.1016/j.proeng.2017.01.109

4. J. Alencastro, A. Fuertes, P. Wilde, Renewable and Sustainable Energy Reviews 81, 883-894 (2018) doi.org/10.1016/j.rser.2017.08.029 
5. B. Zhongab, X. Xingab, P. Lovec, X. Wangab, H. Luoab, Advanced Engineering Informatics 40, 46-57 (2019) doi.org/10.1016/j.aei.2019.02.009

6. H.J. Jeongab, B.H. Kima, S.Y. Junga, Procedia Manufacturing 11, 2139-2146 (2017) doi.org/10.1016/j.promfg.2017.07.345

7. S. Demirkesena, B. Ozorhonb, International Journal of Project Management 35-8, 1639-1654 (2017) doi.org/10.1016/j.ijproman.2017.09.008

8. S. Lukichev, M. Romanovich, Procedia Engineering 165, 1717-1721 (2016) doi.org/10.1016/j.proeng.2016.11.914

9. B.J. Ladewskia, A.J. Al-Bayatib, Journal of Safety Research 69, 193-200 (2019) doi.org/10.1016/j.jsr.2019.03.004

10. M.A. Momeni, S. Yaghoubi, M.R.M. Aliha, Computers \& Industrial Engineering 129, 529-544 (2019) doi.org/10.1016/j.cie.2019.02.007

11. J. Adamczyka, R. Dylewskib, Renewable and Sustainable Energy Reviews 80, 421429 (2017) doi.org/10.1016/j.rser.2017.05.173

12. A.Kh. Baiburin, Procedia Engineering 206, 807-813 (2017) doi.org/10.1016/j.proeng.2017.10.555

13. M. Sedek, A. Serwa, The Egyptian Journal of Remote Sensing and Space Science 19-2, 273-283 (2016) doi.org/10.1016/j.ejrs.2015.12.005

14. A. Dong, M.L. Maher, M.J. Kim, N. Gu, X. Wang, Automation in Construction 18-6, 814-824 (2009) doi.org/10.1016/j.autcon.2009.03.005

15. N. Ahzahar, N.A. Karim, S.H. Hassan, J. Eman, Procedia Engineering 20, 249-255 (2011) doi.org/10.1016/j.proeng.2011.11.162 